SCHOLARS: Journal of Arts \& Humanities

Volume 2, August 2020, pp. 14-26

[Peer-Reviewed, Open Access, Indexed in NepJOL]

Print ISSN: 2773-7829; e-ISSN: 2773-7837

DOI: https://doi.org/10.3126/sjah.v2i0.35009

Central Department of English

Tribhuvan University

Kirtipur, Kathmandu, Nepal

www.cdetu.edu.np/ejournal/

Original Research Article

\title{
Comprehension Monitoring, Appraisal Confidence and Self-efficacy in EFL Reading: A Correlational Study from Nepal
}

\author{
Madhu Neupane Bastola, PhD \\ The Hong Kong Polytechnic University \\ Hong Kong
}

\begin{abstract}
The current study explored the relationships among English as a Foreign Language (EFL) learners' comprehension monitoring, appraisal confidence, reading self-efficacy and EFL reading comprehension performance. First, 203 students reported their comprehension monitoring and reading self-efficacy. Then they took an EFL reading comprehension test and reported their appraisal confidence immediately after answering each question. Students' comprehension monitoring, appraisal confidence and reading self-efficacy were found to be far higher than their average reading comprehension performance. Similarly, the students with a high level of reading comprehension tended to be better at monitoring comprehension and were more self-efficacious than those who performed poorly in the test. Finally, significantly positive correlations were found among comprehension monitoring, appraisal confidence, reading self-efficacy and EFL reading comprehension performance.
\end{abstract}

Keywords: Reading comprehension, comprehension monitoring, appraisal confidence, self-efficacy, English as a foreign language

\section{Introduction}

Knowledge is the basis for any decisions in the present-day knowledge-based economy and reading is one of the main sources of knowledge. Reading is important because "success is much harder to come by without being a skilled reader" (Grabe 5). In English as a Foreign Language (EFL) context, the demand for efficient EFL reading is ever increasing because of the ubiquitous use of information and communication technology, the professional and educational opportunities associated with English and the position of English as a compulsory subject in a wide range of educational settings. The EFL readers have to read different types of texts in different contexts for multiple purposes and the most basic of which is reading for comprehension (Grabe and Stoller 513).

Reading comprehension is a complex process of making the meaning of written texts (Goodman 127) that involves different skills, strategies, abilities and processing of information at different levels (Grabe and Stoller 32). Though processing information at a lower level (e.g., lexical, syntactic and semantic) can be automatic with extensive 


\section{Comprehension Monitoring, Confidence Appraisal and Self-efficacy in EFL Reading 15}

practice, higher-level processing (e.g., understanding, interpreting, inferencing and metacognition) requires a reader's deliberate attention. For better understanding a reading text, the readers need be aware of their own cognitive processes and monitor their comprehension by identifying difficulties in reading and applying appropriate strategies to solve them (Dabarera et al. 463). At the same time, the readers' self-efficacy (i.e., their belief in their own capabilities) (Bandura 2) and appraisal confidence (i.e., their subjective expression of decisions about the degree of likelihood or certainty of future outcomes of their test performance) (Harvey 74) also influence their reading comprehension (Morony et al. 81).

This study was conducted in a public university in Nepal where there are concerns about the students' low proficiency in English. For this reason, the question of how learners' reading abilities can be improved is of great importance. Extant research has shown that students' comprehension monitoring, appraisal confidence and selfefficacy influence their reading ability (Morony et al. 81). However, the reading comprehension ability of EFL learners in general and the relation between their comprehension monitoring, appraisal confidence, self-efficacy and EFL reading comprehension in the Nepali context has been under-researched leaving a blind spot in our understanding. Therefore, this article focused on this less researched aspect in less researched context to provide pedagogical implications for improving learners' reading comprehension ability.

Comprehension monitoring, an important aspect of metacognition, refers to the monitoring of one's own understanding while reading. It is considered to be a major component of reading as it "provides a link between readers' purposes, progress and behavior" (Paris and Meyer 5). Two basic processes involved in comprehension monitoring are the evaluation and regulation of one's own ongoing comprehension processes (Baker 2). According to Wagoner, comprehension monitoring is about knowing about comprehending and knowing how to comprehend (329). The former refers to an awareness of problems in comprehension while the latter refers to the use of strategies to solve the problems. Expert readers are said to monitor their comprehension more consistently than novice readers (Block 320). In contrast, "students with poor monitoring skills. . . either do not notice their miscomprehension or do not take action to remedy their lack of understanding” (Veenman 71). Despite comprehension monitoring being of particular importance to second or foreign language learners, it has revived scant attention.

Some researches examining metacognitive awareness of English as a Second Language (ESL)/EFL learners, in general, have shown that high performing global (topdown) readers were better at monitoring comprehension and performed better in ESL/EFL reading tasks than low performing local (bottom-up) readers (e.g., Carrell 127128; Zhang 279-280; Zhang and Wu 48). Extant research using error detection surveys has shown more proficient ESL learners who are better at comprehension monitoring (Block 320) and use more comprehension monitoring strategies (measured in terms of the percentage of errors identified) than the less proficient ones (Khonamri and Kojidi 107). This research has also reported a significant positive correlation between comprehension monitoring and language proficiency (Han 38; Han and Stevenson 74). Further studies using think-aloud protocols have produced mixed results, some claim that the think-aloud protocol is suitable for all levels of learners (Yang 12) while others argue 


\section{Comprehension Monitoring, Confidence Appraisal and Self-efficacy in EFL Reading 16}

it to be effective only for those with a moderate level of language proficiency and comprehension monitoring skills (McKeown and Gentilucci 144-145).

Both error detection and think-aloud protocol have limitations in measuring learners' comprehension monitoring. The use of the error detection technique is not only difficult in terms of specifying the types and kinds of errors, but also a surprisingly low error detection rate reported in previous studies may or may not suggest a lack of monitoring (Baker 13). At the same time, scholars caution the use of think-aloud protocol as it is highly subjective (Wagoner 337). Some consider it suitable only for learners who are good at introspecting and articulating about their reading (Carrell 122) and are able to verbalize their thoughts (McKeown and Gentilucci 144-45). Research has warned that think-aloud may even be disruptive and distracting to advanced learners and is not practical for a large group of students as it is time-consuming (McKeown and Gentilucci 145; Veenman 75).

To overcome the limitations of error detection and think-aloud protocols, this study made use of the self-report questionnaire in examining the awareness of comprehension monitoring. However, the self-report measure has its own limitations. The learners' awareness of comprehension is necessary but not enough for comprehension monitoring (Veenman 69). At the same time, learners may not always be accurate about what they say they do to monitor their comprehension when they are reading and what they actually do. Therefore, appraisal confidence ratings, which is said to reflect the self-monitoring process of metacognition (Kleitman and Stankov 163), are also incorporated in this research.

Appraisal confidence refers to learners' subjective expression of decisions about the degree of likelihood or certainty of future outcomes of their test performance (Phakiti 76). It is examined through a confidence-rating procedure. Immediately after providing a response to a test item, test-takers are asked to rate their level of appraisal confidence about the accuracy of their answer on a percentage scale, usually ranging from $0 \%$ to $100 \%$ (Phakiti 79). The average score for all the attempted test items is the overall appraisal confidence score. The match between the estimates of correctness and the accuracy of answers is called calibration whereas the mismatch is referred to as miscalibration (Stankov et al. 752).

Studies in the field of psychology (e.g., Stankov and Crawford; Stankov et al.; Stankov and Lee), with their main focus on establishing the nature of appraisal confidence traits, have included some aspects of the English language as components of cognitive ability. A study, involving 824 native speakers of English in Testing English as a Foreign Language Internet-Based Test (TOEFL iBT), showed somewhat positive associations between reading accuracy and appraisal confidence scores (ranging from 0.46 to 0.60 for two different sets of reading tests). Similarly, groups with lower performance accuracy demonstrated higher overconfidence. In the same way, Stankov et al.'s large-scale study $(N=1,786)$ concluded that there was a positive correlation between appraisal confidence and test scores ( $r=0.56$ ) (Stankov and Lee 972).

However, the relationship between appraisal confidence and EFL reading is still in the embryonic stage. A recent study involving 294 EFL students to measure four language areas (listening, grammar, vocabulary and reading) showed a moderate correlation ( $r=0.61$ ) between appraisal confidence and test score with appraisal confidence predicting just above one-third of performance variance. Further research in 
Comprehension Monitoring, Confidence Appraisal and Self-efficacy in EFL Reading 17

this area is required to establish the relationship between appraisal confidence and EFL reading (Phakiti 89-90).

Self-efficacy refers to "belief in one's capabilities to organize and execute the courses of action required to manage prospective situations" (Bandura 2). It determines learners' initiation, efforts and persistence to attain educational goals; increases their expectation for valuable outcomes; promotes self-regulation, self-monitoring and better strategy use; and influences their thinking, feeling and motivation (Zimmerman 204-13). Similarly, belief in personal-efficacy constitutes the key factor in deciding whether learners take agency in their learning (Pajares 543). Research has shown that selfefficacy powerfully affects learners' academic performance in various ways (Mills et al. 417; Pajares 568; Zimmerman 204-13).

Extant research has shown a significant positive correlation between selfefficacy and EFL learning in general. For example, a longitudinal case study found that boys showed a willingness to participate and persisted longer in language learning activities they believed they could do well in and gave up on tasks they considered to be difficult (Wang and Pape 374-75). Further research that specifically explored the relationship between reading self-efficacy and reading comprehension has shown a significant positive correlation between the two though the effect was small (Naseri and Zaferanieh 69-70).

The majority of previous research examining the relationship between selfefficacy and language learning has studied self-efficacy from a general perspective despite its domain-specific nature (Bandura 310). Though the studies reviewed above have contributed to our understanding of the nature of the relationship between selfefficacy and language learning in general, the relationship between reading self-efficacy and EFL reading is largely unexplored. The present research aimed to address these knowledge gaps in the existing literature and sought to answer the following questions:

1. What is the nature of learners' comprehension monitoring, appraisal confidence, reading self-efficacy and EFL reading comprehension performance?

2. How do learners having different levels of EFL reading comprehension performance differ in terms of comprehension monitoring, appraisal confidence and reading self-efficacy?

3. To what extent do learners' comprehension monitoring, appraisal confidence and reading self-efficacy relate to EFL reading comprehension performance?

\section{Methodology \\ Setting and Participants}

This research was carried out at the Department of English Education at a Nepali university located in Kathmandu. The participants were studying for the Master of Education degree with specialization in English. Altogether 210 participants took part in the study, but usable data came from only 203 participants. Out of the 203 participants, 115 (56.65\%) were males and 88 (43.35\%) were females. They were between the ages of 20 and 32 (mean $=24.06$ ) and had studied English for between 10 and 25 years (mean = 15.23) at the time the research was carried out. 
Comprehension Monitoring, Confidence Appraisal and Self-efficacy in EFL Reading 18

\section{Research Instruments: The EFL Reading Comprehension Test}

For the current study, an EFL reading comprehension test was designed. Two expository texts, that is, informational texts were used in this study (Akhondi et al. 368). The texts had a difficulty level of $13^{+}$(Fry 249). The text were seleted two books (Richardson 7-8; Van Doren 187-89). The skills examined by the test are described as follows:

- Identifying Factual Information: Readers are required to locate and identify answers to questions about specific information and details in the passage. In such questions, both the question information and correct answers are found in the text.

- Making Inferences: Readers are required to draw conclusions based on the information in the passage. Such questions require general knowledge, skillful reading and higher-order processing of information on the part of the readers.

- Getting the Meaning of Vocabulary in Context: Readers are required to identify the meaning of a word or phrase as used in the passage.

- Identifying the Main Idea, Purpose, Attitude, or Opinion: Readers are required to identify the main idea or the subject of the whole passage, or the author's attitude or opinion towards the content or main purpose of the text.

- Identifying References: Readers are required to identify the antecedent (a word, phrase or a sentence) to which a pronoun or other expression refers.

- Retrieving Elliptical Information: Readers are required to retrieve missing information by using the context.

The reading comprehension test was piloted with 15 EFL learners. At the piloting stage, the test contained 50 questions, each worth one point. Based on the information obtained from the pilot, fourteen items were deleted and some other items were modified. The finalized reading comprehension test consisted of 36 items each worth one point. The reliability (Cronbach's alpha) of the test was 0.75 . The test techniques included multiplechoice, true/false/not given, matching, filling in the blanks, identifying referents and short answer questions.

\section{Appraisal Confidence Rating Scales}

Theoretically, an appraisal confidence rating scale depends on the number of alternatives given to a multiple-choice question (Phakiti 2016 83). For example, a rating scale contains five points (i.e., $20 \%, 40 \%, 60 \%, 80 \%, 100 \%$ ) for a question with five options and four points (i.e., $25 \%, 50 \%, 75 \%$ and $100 \%$ ) for a question with four options. However, in the EFL reading test designed for this research, some of the questions had alternatives while others were open-ended. Therefore, the same six-point relativefrequency appraisal confidence scale (i.e., $0 \%, 25 \%, 50 \%, 75 \%, 90 \%$ and 100\%) (Phakiti 2016 83) was used for all the questions irrespective of the number of alternatives. The relative-frequency appraisal confidence scale was embedded in each test question. The questions were designed to allow the learners to record both their answers and appraisal confidence estimates. The participants were instructed to rate their appraisal confidence immediately after they answered each question. 
Comprehension Monitoring, Confidence Appraisal and Self-efficacy in EFL Reading 19

\section{Self-efficacy and Comprehension Monitoring in Reading Inventory}

For the purpose of this research, a 40-item self-reported inventory for assessing reading self-efficacy and comprehension monitoring was designed based on the literature. The inventory comprised of three parts: Part A (demographic information), Part B (30 items for measuring reading self-efficacy) and Part C (10 items for measuring comprehension monitoring). It was also piloted with 15 potential participants. In the piloting stage, the inventory contained 42 items. Based on the information obtained from the pilot two items were deleted from part B and the final version contained only 40 items. Part B and Part $\mathrm{C}$ of the inventory are described below:

Part B (Reading Self-efficacy): This section contained 30 items that allowed the participants to report their reading self-efficacy confidence on a 6-point Likert-type scale. The options were $0 \%$ (100\% sure I cannot do), $25 \%$ (25\% sure I can do), $50 \%$ (50\% sure I can do), 75 (75\% sure I can do), 90\% (90\% sure I can do) and 100\% (100\% sure I can do). The questions were divided into four components of reading as described below (Grabe and Stoller 3-31):

- Lower Level Processing of Information: The participants are required to report their reading self-efficacy at the word and sentence level understanding of a text.

- Higher-level Processing of Information: The participants are required to report their reading self-efficacy at the whole text level of understanding such as making inferences and distinguishing facts from opinions.

- $\quad$ Reading for Different Purposes: The participants are asked to report their selfefficacy in reading for different purposes, such as getting a specific piece of information or getting the gist of the text.

- Reading Different Types of Texts: The participants are asked to report their selfefficacy in reading varied types of texts such as English language newspapers and academic articles.

Part C (Comprehension Monitoring): This part contained 10 items that required the participants to report their comprehension monitoring in reading on a 6-point Likert scale: $0 \%$ (I never do this), 25\% (I occasionally do this), 50\% (I sometimes do this), 75\% (I often do this), 90\% (I usually do this) and 100\% (I always do this).

\section{Data Preparation and Instrument Analysis}

Three main steps were taken in preparing the data collected from the reading comprehension test, appraisal confidence rating scales and the inventory. In an SPSS spread sheet, a test score (converted into a percentage) and its appraisal confidence were paired in the data entry followed by reported comprehension monitoring and reading self-efficacy. Descriptive statistics for the data were computed to examine the central tendencies, variability and distribution of raw score data. The data were generally normally distributed. The reliability (Cronbach's alpha) for the test $(\alpha=0.75)$, appraisal confidence ( $\alpha=0.88$ ), reading self-efficacy ( $\alpha=0.91$ ) and comprehension monitoring ( $\alpha$ $=0.79$ ) indicated that the instruments were reliable for the EFL participants of the current study. 
Comprehension Monitoring, Confidence Appraisal and Self-efficacy in EFL Reading 20

\section{Results and Discussion}

Research Question 1: What is the nature of learners' comprehension monitoring, appraisal confidence and reading self-efficacy in relation to EFL reading comprehension performance?

First, Exploratory Factor Analysis (Principal Component Analysis) was conducted to determine the underlying factors of the inventory. In the analysis, factors with loadings less than 0.4 were not displayed. For these data, the KMO values for selfefficacy and comprehension monitoring were 0.88 and 0.80 respectively, showing the adequacy of the sample size for factor analysis (Field 647). The analysis identified four components for self-efficacy, which explained $55.61 \%$ of the variance and two components for comprehension monitoring, which explained $50 \%$ of the variance (see Table 1 and Table 2).

\section{Table 1}

Rotated Component Matrix for Self-efficacy in Reading

\begin{tabular}{|c|c|c|c|c|}
\hline Items & $\begin{array}{l}\text { Lower level } \\
\text { processing }\end{array}$ & $\begin{array}{l}\text { Different } \\
\text { purposes } \\
\text { of reading }\end{array}$ & $\begin{array}{l}\text { Reading } \\
\text { different types } \\
\text { of texts }\end{array}$ & $\begin{array}{l}\text { Higher- } \\
\text { level } \\
\text { processing }\end{array}$ \\
\hline Cronbach's alpha & 0.74 & 0.71 & 0.72 & 0.71 \\
\hline Identifying references & 0.74 & & & \\
\hline Identifying synonymous words & 0.72 & & & \\
\hline $\begin{array}{l}\text { Identifying grammatical } \\
\text { functions of words }\end{array}$ & 0.72 & & & \\
\hline $\begin{array}{l}\text { Guessing meaning of words } \\
\text { from suffixes and prefixes }\end{array}$ & 0.59 & & & \\
\hline Scanning & & 0.76 & & \\
\hline Skimming & & 0.68 & & \\
\hline Relating parts of a text & & 0.65 & & \\
\hline $\begin{array}{l}\text { Summarizing a text for general } \\
\text { meaning }\end{array}$ & & 0.60 & & \\
\hline $\begin{array}{l}\text { Reading English language } \\
\text { newspapers }\end{array}$ & & & 0.79 & \\
\hline $\begin{array}{l}\text { Reading and understanding } \\
\text { other varied texts }\end{array}$ & & & 0.74 & \\
\hline Reading academic articles & & & 0.68 & \\
\hline Enjoying literary reading texts & & & 0.60 & \\
\hline $\begin{array}{l}\text { Evaluating purpose and } \\
\text { coherence of a text }\end{array}$ & & & & 0.78 \\
\hline $\begin{array}{l}\text { Distinguishing main ideas from } \\
\text { supporting details }\end{array}$ & & & & 0.78 \\
\hline $\begin{array}{l}\text { Using information from reading } \\
\text { in writing }\end{array}$ & & & & 0.57 \\
\hline Making predictions & & & & 0.53 \\
\hline
\end{tabular}


Comprehension Monitoring, Confidence Appraisal and Self-efficacy in EFL Reading 21

Table 2

Rotated Component Matrix for Comprehension Monitoring

\begin{tabular}{lll}
\hline & $\begin{array}{l}\text { Identifying } \\
\text { problems }\end{array}$ & $\begin{array}{l}\text { Solving } \\
\text { problems }\end{array}$ \\
\hline Cronbach's alpha & $\mathbf{0 . 7 6}$ & $\mathbf{0 . 7 0}$ \\
I notice when I am not sure I understand the text. & 0.80 & \\
I check my understanding when I come across new & 0.79 & \\
information. & 0.68 & \\
I ask myself if I am reading the text properly. & 0.64 & 0.80 \\
I identify the cause of a problem in understanding a text. \\
$\begin{array}{l}\text { I underline the problematic parts whenever I confront them. } \\
\text { I read the text slowly. }\end{array}$ \\
$\begin{array}{l}\text { I reread the text. } \\
\text { I read backward and forward in the text. }\end{array}$ \\
$\begin{array}{l}\text { I proceed with the hope that the confusion might be } \\
\text { clarified later on. }\end{array}$ \\
$\begin{array}{l}\text { I ignore some parts that I think are not important to } \\
\text { understand the text. }\end{array}$ & 0.64 \\
\hline
\end{tabular}

Table 3

Descriptive Statistics of Comprehension Monitoring, Appraisal Confidence, Reading Self-Efficacy and EFL Reading Comprehension Performance $(N=203)$

Min. Max. Mean Std. Skewness Kurtosis

\begin{tabular}{lrrrrrr}
\hline Comprehension monitoring & 17.60 & 100 & 74.80 & 14.18 & -0.82 & 0.93 \\
Appraisal confidence & 46.81 & 99.43 & 86.84 & 8.28 & -1.09 & -2.35 \\
Reading self-efficacy & 48.06 & 95 & 73.86 & 11.58 & -0.33 & -0.86 \\
$\begin{array}{l}\text { EFL reading comprehension } \\
\text { performance }\end{array}$ & 19.44 & 94.44 & 52.35 & 14.18 & -0.07 & -0.08 \\
\hline
\end{tabular}

As seen in Table 3, with respect to variability, the standard deviations of the constructs ranged from 8.28 (appraisal confidence) to 14.18 (comprehension monitoring and EFL reading performance). It can be observed that the learners' average reported comprehension monitoring ( $M=74.80 \%)$, appraisal confidence $(M=86.84 \%)$ and reported reading self-efficacy $(M=73.86 \%)$ scores were far higher than their EFL reading comprehension performance $(M=52.35 \%)$ which was at a moderate level. The learners, in general, were highly overconfident (the mean difference between appraisal confidence scores and accuracy scores was 34.49).

Research Question 2. How do learners having different levels of EFL reading comprehension performance differ in terms of comprehension monitoring, appraisal confidence and reading self-efficacy?

To find out if there were significant differences among the learners having different levels of EFL comprehension performance in terms of their reported 
comprehension monitoring, appraisal confidence and reading self-efficacy, a one-way ANOVA was examined next. First, the participants were divided into three groups (high scorers, 60-100\%; moderate scorers, 40-59\%; and low scorers, 0-39\%) in terms of their levels of comprehension as determined by their scores in the EFL reading comprehension test. The data for all the groups were generally normally distributed and the variances among groups were equal comprehension monitoring $F(2,200)=0.39$, ns and reading self-efficacy $F(2,200)=2.28$, $n s$. However, for appraisal confidence the variances were significantly different in the three groups, $F(1,200)=4.90, p<0.01$. Therefore, a one-way ANOVA was examined for comprehension monitoring and reading self-efficacy only.

There were statistically significant differences between the three groups of participants in terms of self-reported comprehension monitoring $(F[2,200]=5.70, p<$ $0.01, \eta 2=0.05)$ and reading self-efficacy $\left(F[2,200]=6.01, p<0.01, \eta^{2}=0.05\right)$. The eta-squared $\left(\eta^{2}\right)$ of 0.05 in both cases indicates that $5 \%$ of the variance in EFL reading comprehension performance can be explained by comprehension monitoring and reading self-efficacy each, which indicates the low level of effect. To identify where the statistically significant differences occurred among the groups, a Bonferroni post hoc test was performed. Statistically significant differences were observed between high scorers and low scorers ( $p<0.05, d=0.66$ ) in comprehension monitoring. The Cohen's $d$ value of 0.66 shows the large effect size of comprehension monitoring on reading comprehension performance, indicating that there was a non-overlap of $38.2 \%$ in the score distribution of high scorers and low scorers in terms of comprehension monitoring. The findings are in line with previous studies in which more proficient learners were found to be better at comprehension monitoring (Block 335; Han 38; Zhang 279; Zhang and $\mathrm{Wu} 37)$.

Similarly, the results of one-way ANOVAs showed significant differences between high and low scorers $(p<0.05, d=0.69)$ as well as between moderate and low scorers ( $p<0.05, d=0.48)$ in terms of reading self-efficacy. The Cohen's $d$ value of 0.69 , indicated there was a non-overlap of $38.2 \%$ between the scores of high scorers and low scorers in terms of reading self-efficacy. Similarly, Cohen's $d$ value of 0.48 indicated a medium size effect with a non-overlap of $27.4 \%$ in the scores of the two groups. This finding is in line with previous literature in which significant differences were reported between high and low scorers in terms of reading self-efficacy (Tilfarlioglu and Cinkara 1284).

Research Question 3: To what extent do learners' comprehension monitoring, appraisal confidence and reading self-efficacy relate to EFL reading comprehension performance?

To examine the relationship among comprehension monitoring, appraisal confidence, reading self-efficacy and EFL reading performance, Pearson Product Moment Correlations were calculated. The correlation coefficients were also used to measure the effect size of each independent variable on the dependent variable with values of \pm 0.1 presenting a small, \pm 0.3 a medium and \pm 0.5 a large size effect (Field 170). The results of the analysis are summarized in Table 4. 
Comprehension Monitoring, Confidence Appraisal and Self-efficacy in EFL Reading 23

\section{Table 4}

The Relationship among Comprehension Monitoring, Appraisal Confidence, Reading Self-Efficacy and EFL Reading Comprehension Performance

\begin{tabular}{lcrr}
\hline & $\begin{array}{r}\text { Comprehension } \\
\text { monitoring }\end{array}$ & $\begin{array}{r}\text { Appraisal } \\
\text { confidence }\end{array}$ & $\begin{array}{r}\text { Reading self- } \\
\text { efficacy }\end{array}$ \\
\hline $\begin{array}{l}\text { EFL reading } \\
\text { comprehension } \\
\text { performance }\end{array}$ & $0.25^{* *}$ & $0.35^{* *}$ & $0.23^{* *}$ \\
Reading self-efficacy & $0.50^{* *}$ & $0.29^{* *}$ & \\
Appraisal confidence & $0.16^{*}$ & & \\
& & &
\end{tabular}

As can be seen in Table 4, all the correlations are positive and significant. The correlations between comprehension monitoring, appraisal confidence and reading selfefficacy ranged from 0.16 to 0.50 , which shows that these three constructs are independent but related. Therefore, an increase in one of these constructs tends to bring an increase in each of the others. Similarly, comprehension monitoring $\left(R^{2}=0.06, p<\right.$ $0.01)$, appraisal confidence $\left(R^{2}=0.12, p<0.01\right)$ and reading self-efficacy $\left(R^{2}=0.06, p<\right.$ 0.01 ) indicated that these three constructs had a low but significant positive effect on EFL reading comprehension performance. These statistically significant correlations implied that the learners who performed better in the test tended to rate their appraisal confidence more highly, monitor their comprehension better and be more self-efficacious in reading than those who did poorly.

Of all the constructs, appraisal confidence correlated best with EFL reading comprehension performance ( $\left.r=0.35, R^{2}=0.12, p<0.01\right)$. This finding is in general agreement with `previous studies, which have reported significant positive correlations between appraisal confidence and accuracy scores in reading comprehension, though the correlations were mostly found to be moderate in those studies (Kleitman and Gibson; Stankov et al. 756; Stankov and Lee 973). The difference in the degree of correlation between appraisal confidence and EFL reading comprehension performance in this research from that of the previous literature might be explained by differences in the nature of the participants (First/second language versus foreign language) and the average scores of the participants (high versus low). The observation explains that poor performance and guessing go hand in hand.

In the same way, weak and significantly positive correlation between comprehension monitoring and EFL reading comprehension performance found in this research is in line with the findings of previous studies (Block 335; Carell 128; Zhang, 279). Similarly, weak but statistically significant positive correlation between reading self-efficacy and EFL reading comprehension performance corroborates the findings of previous studies (Stankov et al. 756). Overall, this analysis shows that comprehension monitoring, appraisal confidence and reading self-efficacy had significant positive correlations with EFL reading comprehension performance, with appraisal confidence showing the highest and reading self-efficacy showing the lowest degree of correlation. 
Comprehension Monitoring, Confidence Appraisal and Self-efficacy in EFL Reading 24

\section{Implications and Limitations}

The current research has some important pedagogical implications for EFL reading. As active reading does not involve understanding everything but involves monitoring comprehension (Casanave 299), learners should be made aware of monitoring as a part of good reading. Similarly, appraisal confidence measures might be incorporated into reading assessment for making learners' realistic about what they know and what they do not know. Given the significant positive correlation between reading self-efficacy and EFL reading comprehension performance, raising learners' levels of self-efficacy would bring an improvement in their EFL reading comprehension performance. Knowledge of learners' comprehension monitoring, appraisal confidence and reading self-efficacy beliefs in their abilities to process printed information could help EFL instructors determine the specific areas from which learners' inadequacies stem and, in turn, develop appropriate teaching practices in EFL courses. To sum up, this research may provide EFL instructors with valuable information about EFL learners' metacognitive and self-belief factors that may promote EFL reading comprehension.

Although this study attempted to explore the relationships among comprehension monitoring, appraisal confidence, reading self-efficacy and EFL reading performance, it is likely that the instruments used and the nature and selection of the participants influenced the findings presented here. It is also acknowledged that the data were collected from a single department of a Nepali university and that participation in the study was voluntary. Self-selection bias on the part of the EFL learners might have affected the validity of the data. Furthermore, this survey research was based on quantitative data only. A mixed-methods study would do better to understand the associations among the constructs examined in the current study. Therefore, caution is urged in generalizing any inferences about the relationships among EFL learners' comprehension monitoring, appraisal confidence, reading self-efficacy and EFL reading comprehension performance.

\section{Works Cited}

Akhondi, Masoumeh et al. "How to Teach Expository Text Structure to Facilitate Reading Comprehension.” The Reading Teacher, vol. 64, no. 5, Feb. 2011, pp. 368-72.

Baker, Linda. "The Development of Metacognitive Knowledge and Control of Comprehension: Contributors and Consequences.” Improving Comprehension through Metacognitive Reading Strategy Instruction, edited by K. Mokhtari, Rowman and Littlefield, 2016, pp. 17-48.

Block, Bellen L. "See How They Read: Comprehension Monitoring of L1 and L2 Readers.” TESOL Quarterly, vol. 26, no. 2, 1992, pp. 319-343.

Carrell, Patricia L. "Metacognitive Awareness and Second Language Reading." The Modern Language Journal, vol. 73, no. 2, 1989, pp. 121-134.

Casanave, Christine Pearson. "Comprehension Monitoring in ESL Reading: A Neglected Essential.” TESOL Quarterly, vol. 22, no. 2, 1988, pp. 283-302.

Dabarera, Carol, et al. "The Impact of Metacognitive Scaffolding and Monitoring on Reading Comprehension.” System, vol. 42, Feb. 2014, pp. 462-473.

Fry, Edward. "Fry's Readability Graph: Clarifications, Validity and Extension to Level 17." Journal of Reading, vol. 21, no. 3, 1977, pp. 242-252. 


\section{Comprehension Monitoring, Confidence Appraisal and Self-efficacy in EFL Reading 25}

Goodman, Kenneth S. "Reading: A Psycholinguistic Guessing Game.” Journal of the Reading Specialist, vol. 6, no. 4, May 1967, pp. 126-135.

Grabe, William. Reading in a Second Language: Moving from Theory to Practice. Cambridge UP, 2009.

Grabe, William and Fredricka L. Stoller. Teaching and Researching Reading. 2nd ed., Longman, 2011.

Han, Feifei. "Comprehension Monitoring in Reading English as a Foreign Language.” New Zealand Studies in Applied Linguistics, vol. 18, no. 1, 2012, pp. 36-49.

Han, Feifei and Marie Stevenson. "Comprehension Monitoring in First and Foreign Language Reading.” University of Sydney Papers in TESOL, vol. 3, 2008, pp. 73-110.

Harvey, Nigel. “Confidence in Judgement.” Trends in Cognitive Sciences, vol. 1, no. 2, 1997, pp. 78-82.

Khonamri, Fatemeh and Elahe Mahmoudi Kojidi. "Metacognitive Awareness and Comprehension Monitoring in Reading Ability of Iranian EFL Learners." Profile, vol. 13, no. 2, 2011, pp. 99-111.

Kleitman, Sabina and Jennifer Gibson. "Metacognitive Beliefs, Self-Confidence and Primary Learning Environment of Sixth Grade Students.” Learning and Individual Differences, vol. 21, no. 6, 2011, pp. 728-735.

Kleitman, Sabina and Lazar Stankov. "Self-Confidence and Metacognitive Processes." Learning and Individual Differences, vol. 17, no. 2, 2007, pp. 161-173.

McKeown, Regina G. and James L. Gentilucci. “Think-Aloud Strategy: Metacognitive Development and Monitoring Comprehension in the Middle School SecondLanguage Classroom.” Journal of Adolescent \& Adult Literacy, vol. 51, no. 2, 2007, pp. 136-147.

Mills, Nicole, et al. "Self-Efficacy of College Intermediate French Students: Relation to Achievement and Motivation.” Language Learning, vol. 57, no. 3, 2007, pp. 417-442.

Morony, Suzanne, et al. "Predicting Achievement: Confidence vs Self-Efficacy, Anxiety and Self-Concept in Confucian and European Countries.” International Journal of Educational Research, vol. 58, 2013, pp. 79-96.

Naseri, Mahdieh and Elaheh Zaferanieh. "The Relationship between Reading SelfEfficacy Beliefs, Reading Strategy Use and Reading Comprehension Level of Iranian EFL Learners.” World Journal of Education, vol. 2, no. 2, 2012.

Pajares, Frank. "Self-Efficacy Beliefs in Academic Settings." Review of Educational Research, vol. 66, no. 4, 1996, pp. 543-578.

Paris, Scott, G. and Meyer II Meyer. "Comprrehension Monitoring, Memory and Study Strategies of Good and Poor Readers.” Journal of Reading Behaviour, vol. XIII, no. 1, 1981, pp. 5-22.

Phakiti, Aek. "Test Takers’ Performance Appraisals, Appraisal Calibration and Cognitive and Metacognitive Strategy Use.” Language Assessment Quarterly, vol. 13, no. 2, 2016, pp. 75-108.

Richardson, Will. Blogs, Wikis, Podcasts and Other Powerful Web Tools for Classrooms, 3rd ed. Corwin, 2010. 


\section{Comprehension Monitoring, Confidence Appraisal and Self-efficacy in EFL Reading 26}

Stankov, Lazar, et al. "Confidence: A Better Predictor of Academic Achievement than Self-Efficacy, Self-Concept and Anxiety?” Learning and Individual Differences, vol. 22, no. 6, 2012, pp. 747-758.

Stankov, Lazar and John D. Crawford. "Self-Confidence and Performance on Tests of Cognitive Abilities.” Intelligence, vol. 25, no. 2, 1997, pp. 93-109.

Stankov, Lazar and Jihyun Lee. “Confidence and Cognitive Test Performance.” Journal of Educational Psychology, vol. 100, no. 4, 2008, pp. 961-976.

Tilfarlioglu, Filiz Yalcin and Fatma Seyma Ciftci. "Supporting Self-Efficacy and Learner Autonomy in Relation to Academic Success in EFL Classrooms (A Case Study).” Theory and Practice in Language Studies, vol. 1, no. 10, 2011.

Van Doren, Charles Lincoln. "Twentieth Century: The Triumph of Democracy.” History of Knowledge: Past Present and Future. Ballantine Books, 1992, pp. 25-30.

Veenman, Marcel V. J. "Assessing Metacognition in Reading Processes: Online versus Offline Processes.” Improving Reading Comprehension through Metacognitive Reading Strategies Instruction, edited by K. Mokhatari, Rowman and Littlefield, 2016, pp. 67-85.

Wang, Chuang and Stephen J. Pape. “A Probe into Three Chinese Boys' Self-Efficacy Beliefs Learning English as a Second Language.” Journal of Research in Childhood Education, vol. 21, no. 4, 2007, pp. 364-377.

Zhang, Lawrence Jun. “Awareness in Reading: EFL Students’ Metacognitive Knowledge of Reading Strategies in an Acquisition-Poor Environment.” Language Awareness, vol. 10, no. 4, 2001, pp. 268-288.

Zhang, Lawrence Jun and Aijiao Wu. "Chinese Senior High School EFL Students' Metacognitive Awareness and Reading-Strategy Use.” Reading in a Foreign Language, vol. 21, no. 1, 2009, pp. 37-59.

Zimmerman, Barry, J. "Self-Efficacy and Educational Development.” Self-Efficacy in Changing Societies, Cambridge UP, 1995, pp. 202-231. 